\title{
Sweet taste pleasantness is modulated by morphine and naltrexone
}

Article

Accepted Version

Eikemo, M., Løseth, G. E., Johnstone, T., Gjerstad, J., Frode, W. and Leknes, S. (2016) Sweet taste pleasantness is modulated by morphine and naltrexone. Psychopharmacology, 233 (21). pp. 3711-3723. ISSN 1432-2072 doi:

https://doi.org/10.1007/s00213-016-4403-x Available at https://centaur.reading.ac.uk/66299/

It is advisable to refer to the publisher's version if you intend to cite from the work. See Guidance on citing.

To link to this article DOI: http://dx.doi.org/10.1007/s00213-016-4403-x

Publisher: Springer Verlag

All outputs in CentAUR are protected by Intellectual Property Rights law, including copyright law. Copyright and IPR is retained by the creators or other copyright holders. Terms and conditions for use of this material are defined in the End User Agreement.

\section{www.reading.ac.uk/centaur}

\section{CentAUR}

Central Archive at the University of Reading 
Reading's research outputs online 


\title{
Sweet taste pleasantness is modulated by morphine and naltrexone
}

\author{
Marie Eikemo $^{1,2,3 *}$, Guro E. Løseth ${ }^{3}$, Tom Johnstone ${ }^{4}$, Johannes Gjerstad ${ }^{5,6}$ Frode Willoch $^{6}$, Siri Leknes ${ }^{3,7}$
}

\author{
Affiliations \\ ${ }^{1}$ Norwegian Center for Addiction Research (SERAF), Department of Medicine, \\ University of Oslo, Norway \\ ${ }^{2}$ Division of Mental Health and Addiction, Oslo University Hospital, Oslo, Norway \\ ${ }^{3}$ Department of Psychology, University of Oslo, Norway \\ ${ }^{4}$ School of Psychology and CLS, University of Reading, Reading, UK \\ ${ }^{5}$ Norwegian Institute of Occupational Health (STAMI) Oslo, Norway \\ ${ }^{6}$ Department of Basic Medical Sciences, University of Oslo, Norway \\ ${ }^{7}$ The Intervention Center, Oslo University Hospital, Norway \\ *Correspondence should be addressed to Marie Eikemo \\ Email:m.h.eikemo@medisin.uio.no \\ Address: Norwegian Centre for Addiction Research \\ University of Oslo, Norway \\ PO BOX 1039 Blindern, 0315 Oslo
}

Keywords: Opioid System, Food, Morphine, Naltrexone, Human

Conflict of interests: The authors declare no competing or conflicting financial interests.

Funding: The study was supported by grants from the Norwegian Research Council (ES455867) and a Ph.D. grant from the South-Eastern Norway Regional Health Authority (2013053).

Acknowledgements: We are grateful to Øivind Skare for help with setting up the mixed effects analyses. We thank Jeppe Riegels, Ingunn Olsen, Olga Chelnokova and Hedda Gjertsen for help with data collection. We thank Elisabeth Øiestad, Vigdis Vindenes and Liliana Bach at the Norwegian Institute for Public Health for help with determining medication doses and analyses of biological data. The study is indirectly supported by Aleris Healthcare, Norway, financing the research position of Frode Willoch at the University of Oslo. 


\section{Abstract}

Rodent models highlight the key role of $\mu$-opioid receptor (MOR) signaling in palatable food consumption. In humans however, the effects of MOR stimulation on eating and food liking remain unclear. In a bidirectional psychopharmacological cross-over study, 49 healthy men underwent a sweet taste paradigm following double-blind administration of the MOR agonist morphine, placebo, and the opioid antagonist nalt rexone. We hypothesized that behaviors regulated by the endogenous MOR system would be enhanced by MOR agonism, and decreased by antagonism. The strongest drug effects were expected for the sweetest (high-calorie) sucrose solution, as reported in rodents. However, very sweet sucrose-water solutions are considered sickly and aversive by many people (called sweet dislikers). Since both sweet likers and dislikers were tested, we were able to assess whether MOR manipulations affect pleasantness ratings differently depending on both subjective and objective value. As hypothesized, MOR stimulation with morphine increased pleasantness of the sweetest of five sucrose solutions, without enhancing pleasantness of the lower-sucrose solutions. For opioid antagonism, an opposite pattern was observed for the sweetest drink only. This bidirectional effect of agonist and antagonist treatment is consistent with rodent findings that MOR manipulations most strongly affect the highestcalorie foods. Importantly, the observed drug effects on pleasantness of the sweetest drink did not differ between sweet likers and dislikers. We speculate that the MOR system promotes survival in part by increasing concordance between the objective (caloric) and subjective (hedonic) value of food stimuli, so that feeding behaviour becomes more focused on the richest food available. 


\section{Introduction}

Sweet taste is a primary reward, inducing stereotypical, positive facial displays across mammals and in newborn humans (Berridge 2000). The $\mu$-opioid receptor (MOR) system regulates food preference and intake based on its rewarding properties (hedonic eating) in several animal models (Berridge and Kringelbach 2008; Taha et al. 2006). In rodents, endogenous $\mu$ opioid release is strongly increased by palatable food intake (DiFeliceantonio et al. 2012). Similarly, exogenous stimulation of MORs increases intake (DiFeliceantonio et al. 2012; Doyle et al. 1993; Evans and Vaccarino 1990), whereas antagonist drugs reduce intake of palatable foods (Cleary et al. 1996; Giraudo et al. 1993). However, although opioid antagonism also reduces food intake in healthy humans (Arbisi et al. 1999; Bertino et al. 1991; Levine et al. 2003; Trenchard and Silverstone 1983; Yeomans and Gray 1997; Yeomans and Wright 1991; Ziauddeen et al. 2013, but see Hetherington et al., 1991 \& Scinska et al., 2000), the effects of MOR stimulation are as yet unknown (Drewnowski et al. 1992; Morley et al. 1985; Yeomans and Gray 2002).

In rodents, the strongest effects of MOR manipulations are observed for the most palatable foods such as sucrose water and chocolate pellets (e.g. Doyle et al. 1993; Giraudo et al. 1993). Increased sucrose content is usually operationalized as increased reward. However, when humans rate the subjective pleasantness of sweet tastes, some report pleasure whereas others find intense sweetness sickly and aversive. Hence, humans can be classified as sweet likers or dislikers based on whether or not they show increased liking with increased sucrose content (Asao et al. 2015; Looy et al. 1992). Thus for sweet dislikers, there is a discrepancy between subjective (hedonic) and objective (caloric) reward.

Here, we assessed how MOR stimulation affects sweet taste perception in healthy humans, contrasting the effects of morphine to placebo and the opioid antagonist naltrexone in the same 
sample. We chose a double-blind bidirectional pharmacological design, reasoning that behaviors regulated by the endogenous MOR system would be enhanced by MOR agonism, and decreased by antagonism (as measured by the linear contrast morphine $>$ placebo $>$ naltrexone). Forty-nine healthy males underwent an in-house version of the commonly used Sweet Taste Test (STT) which measures sweet taste liking (pleasantness ratings) and intensity perception of differing concentrations of sucrose dissolved in water (see e.g. Kampov-Polevoy et al. 2014; Looy et al. 1992).

We hypothesized that compared to placebo MOR stimulation (per oral $10 \mathrm{mg}$ morphine) would increase, whereas opioid antagonism (50 mg naltrexone) would decrease, sweet taste liking without affecting taste intensity. Sweetness intensity perception and taste thresholds were not affected by opioid antagonism in previous reports employing sweet taste paradigms (Bertino et al. 1991; Yeomans and Gray 1996). Based on the animal literature showing specific effects of MOR on palatable food consumption, we expected the strongest effects of MOR drugs on liking of the sweetest drink. Importantly, since the sweetest drink was perceived as pleasant in sweet likers and aversive in sweet dislikers, we were able to assess whether MOR manipulation would affect pleasantness ratings differently depending on sweet liking phenotype. Participants were genotyped with regard to the single nucleotide polymorphism (SNP) A118G (rs1799971) of the MOR gene (OPRM1) to account for possible influence of genetic variability on effects of drug manipulations. 


\section{Methods and Materials}

\section{Participants}

Forty-nine participants, recruited in two stages as described below, completed testing with morphine, placebo and naltrexone. Only males were included in this repeated-measures study to avoid potential drug interaction with circulating levels of estradiols and GnRH pulsability in females (Smith et al. 1998). Participants were screened to exclude those with a history of depression or other major psychiatric illness, current ongoing psychiatric or medical illness, multiple complex allergies, prior drug dependence or addiction, current use of medication (except from antihistamines). Exclusion criteria also included: history of chronic use of opioids, use of any strong opioids in the two last years, and use of codeine drugs in the last four months. All participants reported to have normal or corrected-to-normal vision. Participants were requested not to consume alcohol on the evening before each test day and asked to refrain from eating and using tobacco in the hour before each test session. They were advised not to drive a vehicle for 6 hours after drug administration.

Select relevant items from AUDIT and DUDIT (Alcohol/Drug Use Disorders Identification Test) were used to assess drug and alcohol consumption (Berman et al. 2005; Saunders et al. 1993). Participants reported consuming an average of $7.7(\mathrm{SD}=5.9)$ alcoholic units per week (range: 0-24 units). Life-time use of illegal drugs: 35 volunteers reported use of cannabinoids, 15 in the last twelve months. Seven volunteers reported use of amphetamines, nine volunteers reported use of cocaine/crack, and nine reported use of hallucinogens (ecstasy, LSD). One participant reported life time use of illegal opiates. Thirteen of the volunteers smoked cigarettes daily, and 12 smoked occasionally. Six volunteers reported life-time use of prescription morphine and 28 participants reported previous use of codeine drugs for acute pain relief. 
Data collection was performed in two stages using identical test procedures. Data were first collected from 32 male participants. One participant was excluded from the study due to a positive opiate urine screening test and another failed to complete all three sessions, yielding 30 datasets in stage one (5 OPRM1 A118G G-carriers and 25 AA homozygotes). To enable comparison of OPRM1 A118G genotype subgroups, in the second data collection stage we oversampled G-carriers. From a pre-genotyped group of 136 men, 20 healthy men were recruited and 19 completed all three sessions (17 G-carriers and two AA homozygotes). The final sample size was thus 49 participants (27 A/A, 22 G-carriers; see Table 1 for participant characteristics).

Table 1. Sample characteristics

\begin{tabular}{lllllll}
\hline \multirow{2}{*}{ Participant information } & \multicolumn{2}{c}{ Overall } & \multicolumn{3}{c}{ AA $(\mathrm{n}=27)$} & \multicolumn{2}{c}{ AG $(\mathrm{n}=22)$} \\
\cline { 2 - 7 } & Mean & SD & mean & SD & mean & SD \\
\hline Age (years) & 24.65 & 3.90 & 26.60 & 4.60 & 22.70 & 3.20 \\
Weight (kg) & 79.45 & 10.85 & 81.70 & 12.20 & 77.20 & 9.50 \\
Height (meter) & 1.82 & 0.07 & 1.84 & 0.06 & 1.80 & 0.07 \\
BMI (weight/heigh ${ }^{2}$ ) & 23.55 & 2.90 & 24.00 & 2.80 & 23.10 & 3.00 \\
Alcohol units per week & 7.70 & 5.95 & 6.30 & 5.30 & 9.10 & 6.60 \\
Binges (per month: > 6 units) & 1.55 & 0.83 & 1.37 & 0.70 & 1.74 & 0.96 \\
\hline
\end{tabular}

Data are presented in overall summary and as divided by genotype. Summaries are based on selfreport. One alcoholic unit was described as a small beer ( 0.33 liter) or a small glass of wine.

Genotype stratification. DNA was extracted from saliva or blood by standard DNA isolation kits; OrageneDNA / FlexiGene (Qiagen, Hilsen, Germany / DNA Genotech Inc. Kanata, Ontario, Canada) according to the manufacturer's instructions. The participants were genotyped with regard to the SNP A118G (rs1799971) in the opioid receptor mu 1 (OPRM1). As previously described (Olsen et al. 2012a), SNP genotyping was carried out using predesigned TaqMan SNP genotyping assays (Applied Biosystems, Foster City, CA, USA). Approximately $10 \mathrm{ng}$ genomic DNA was amplified in a $5 \mu 1$ reaction mixture in a 384-well plate containing 1x TaqMan genotyping master mix (Applied Biosystems) and 1x assay mix, the latter containing the 
respective primers and probes. Genotypes were determined using the SDS 2.2 software (Applied Biosystems). Approximately $10 \%$ of the samples were re-genotyped and the concordance rate was $100 \%$.

\section{Procedure}

Experimental procedures were approved by the Regional Ethics Committee (2011/1337/REK sør-øst D). Participants gave informed consent and were informed that they could withdraw from the study at any time. Each participant was tested after receiving a different drug on three different days (double-blind administration, with a minimum wash-out of seven days). Each session lasted approximately three hours. After giving written consent, participants were asked to submit a urine sample for opiate screening (MOP Opiate300 Test Strip; SureScreen Diagnostics Ltd, Derby, UK). If the drug toxicology was negative participants received one of the three drugs after completing state-relevant questionnaires. The experimental tasks were completed between 60 and 150 minutes after drug administration. The sweet taste test was always administered at the end of the experimental session after tests of monetary reward, social touch reward and facial attractiveness (Chelnokova et al. 2014) as sucrose consumption has been shown to modulate endogenous opioid release (DiFeliceantonio et al. 2012). To confirm drug uptake, a blood sample was taken at the end of the experiment session. At the end of the third session, participants were debriefed and asked to guess the identity of the drug received in each session. These data showed that on average, participants identified the drug received correctly $33 \%$ of the time, indicating successful blinding. Participants were reimbursed 400-500 NOK (about 60 US dollars) per session, partly depending on task performance in a monetary reward task.

Drug administration. Morphine is a selective $\mu$-opioid receptor agonist and the most widely chosen analgesic for moderate to severe pain (Vindenes et al. 2006). To minimize subjective drug 
effects we used 10 mg per oral morphine (Morfin ${ }^{\circledR}$, Nycomed Pharma, Asker, Norway). The bioavailability of oral morphine is on average $30-40 \%$. Morphine has maximal effect (t-max) at 1-2 hours after oral administration, and a half-life of 2-4 hours (Lugo and Kern 2002). Naltrexone is a non-specific competitive opioid antagonist with a high affinity to $\mu$ - and $\kappa$-opioid receptors. Naltrexone blocks the effects of endogenous (e.g. endorphins) and exogenous opioids (e.g. heroin) and is used in treatment of drug and alcohol addiction. The maximal plasma concentration of oral naltrexone is reached after one hour (Verebey et al. 1976). We used $50 \mathrm{mg}$ per oral naltrexone (Adepend, Orpha-Devel, Purkersdorf, Austria), a standard dosage that has been shown to efficiently block the majority of opioid receptors in the brain (Lee et al. 1988) with only minor side-effects in healthy individuals (Miotto et al. 2002; Yeomans and Gray 2002). Placebo pills were cherry-flavored breath mints. A small amount of the flavored placebo pills were added to the drug dosages to avoid any recognition of medication taste. The test interval between 60 and 150 minutes after drug intake was deduced by comparing the time of maximal bioavailability of oral morphine and naltrexone.

Subjective state measures. Measurement of mood and subjective state (including happiness, anxiety, irritability, feeling good, hunger and nausea) were collected four times during each session. Items were rated on electronic visual analogue scales (VAS) prior to drug administration (t 0), before the experiment session ( $\mathrm{t}$ 60), mid-way through experiment session (t 100) and after completion of all tasks ( $\mathrm{t}$ 140). All questionnaires were made in MATLAB (version 7.10.0. Natick, Massachusetts: The MathWorks Inc., 2010).

Motor Coordination task. To assess potential drug effects on alertness and motor function, participants completed an eye-hand coordination test mid-way through each session 
(Bradykinesia Akinesia Incoordination task (Giovannoni et al. 1999)). Participants were instructed to alternate between pressing two keys on a standard keyboard (15 cm apart) as quickly and accurately as possible for 60 seconds using their dominant hand. A general performance measure output, the Dysmetria Score (a weighted index of speed and accuracy; Giovannoni et al. 1999),was used to compare motor function across drug conditions.

The sweet taste test. To test the effects of opioid agonism and antagonism on sweet taste liking, we used a sweet taste test (STT, see Fig. 1) adapted from well-established paradigms for assessing sweet taste liking/hedonic response to sweet taste (see e.g. Kampov-Polevoy et al. 1997; Looy et al. 1992). Participants used an electronic VAS (MATLAB) to rate sucrose solutions on (i) sweetness intensity ("How sweet is the drink?" anchors: not sweet at all - extremely sweet) and (ii) pleasantness (“How much do you like the drink?" anchors: dislike strongly - like very much). Five different sucrose solutions were used $(0.05,0.10,0.20,0.42$, and 0.65 molar (M). For comparison Coca Cola classic is a $0.33 \mathrm{M}$ solution). Each solution was presented three times in each session in a pseudo-randomized order and each drink occurred only once in each of three runs. Participants were requested to taste, but not swallow, the solutions, which were presented in transparent cups $(15 \mathrm{ml})$. Between each trial, a message on the screen reminded participants to rinse their mouth with water before proceeding. The experimenter gave verbal instructions and was present during the first trials to ensure that the instructions were clear. The written instruction "In this task you will taste different drinks. After each drink you will be asked to evaluate different qualities of the drink. Rinse your mouth and spit between tasting each drink" remained visible at the top of the screen throughout the test. 
a

1. "How sweet is the drink?"

Not at all

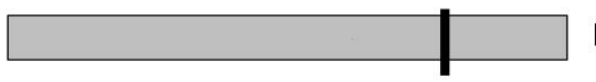

Extremely

2. "How much do you like the drink?"

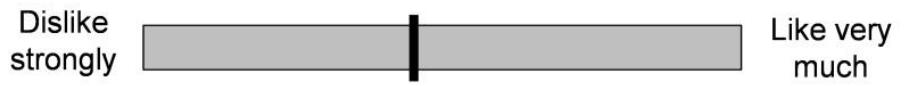

3. "Rinse your mouth with water and click 'next' to continue" b
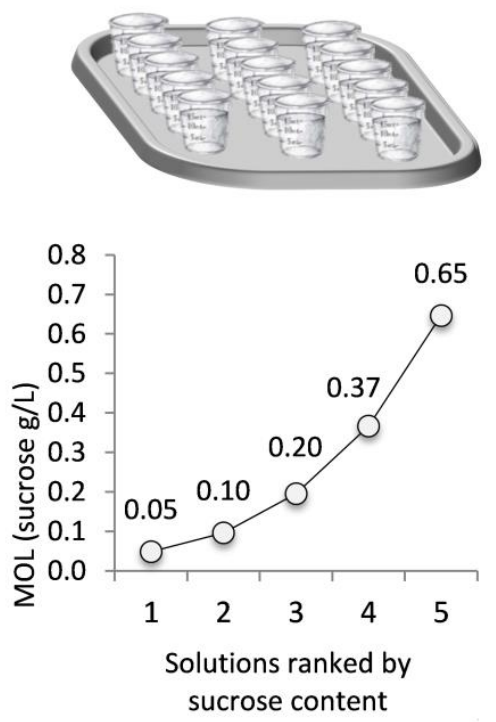

Fig. 1 a) Illustration of the three events in a trial. Participants rated perceived sweetness of a solution, then the pleasantness before rinsing their mouth with water and proceeding to the next trial. b) Drinks of five different sucrose solutions were presented on a tray. Participants were instructed to expectorate in large opaque disposable cups between trials.

Operationalization of sweet liking phenotypes. Sweet liking phenotype is considered a stable trait (Looy et al., 1992) which has been associated with impulsivity (Weafer et al., 2014) and alcohol and cocaine intake (Kampov-Polevoy et al., 2001; Janowsky et al., 2003). On the basis of its heritability and association with response to opioid antagonist treatment, sweet liking phenotype has even been proposed as a behavioral marker for central MOR sensitivity (Kampov-Polevoy et al., 2006). Different methods have been used to operationalize who constitutes a sweet liker or sweet disliker. The two most commonly used practices are (i) Dividing participants into subgroups based on whether their pleasantness ratings generally increase or decrease with increasing sucrose content (e.g. Looy et al. 1992) and (ii); Categorizing only individuals who prefer the very sweetest solution as sweet likers (e.g. Weafer et al. 2014). Here we chose to divide 
participants into sweet likers and sweet dislikers depending on the (positive or negative) correlation between sucrose content and mean pleasantness rating per drink in the placebo session.

Sweet liking phenotype group characteristics. Participants with a positive correlation between sucrose content and pleasantness ratings in the placebo condition were classified as sweet likers $(\mathrm{n}=23$, median $r=0.84, \mathrm{SD}=0.28$, range (min, max): 0.042, 0.995). Conversely, participants with a negative correlation were classified as sweet dislikers $(\mathrm{n}=26$, median $r=-0.91, \mathrm{SD}=0.23$, range: $-0.089,-0.993$, see Fig. 2 and Table 3 for means and SD per drink and drug). Eleven of the 22 G-carriers of the OPRM1 A118G SNP were classified as sweet likers, and 11 of 27 AA homozygous participants were sweet likers. A chi square test showed that the difference was not significant $\left(\mathrm{X}^{2}=.42, \mathrm{p}=.517\right)$.

Mixed effects models of pleasantness and intensity ratings from the placebo sessions only were conducted to assess differences between the phenotype groups at baseline. Pairwise Contrasts from the intensity ratings showed no significant differences between the two phenotype groups on any sucrose level (Fig. 2a, Table 3). Contrasts from the pleasantness analysis confirmed that the two phenotype groups differed on pleasantness evaluations of all but the $0.2 \mathrm{M}$ concentration (see Figure 2b and Table 3; also see Supplementary Materials for details of the analysis and results). 
a

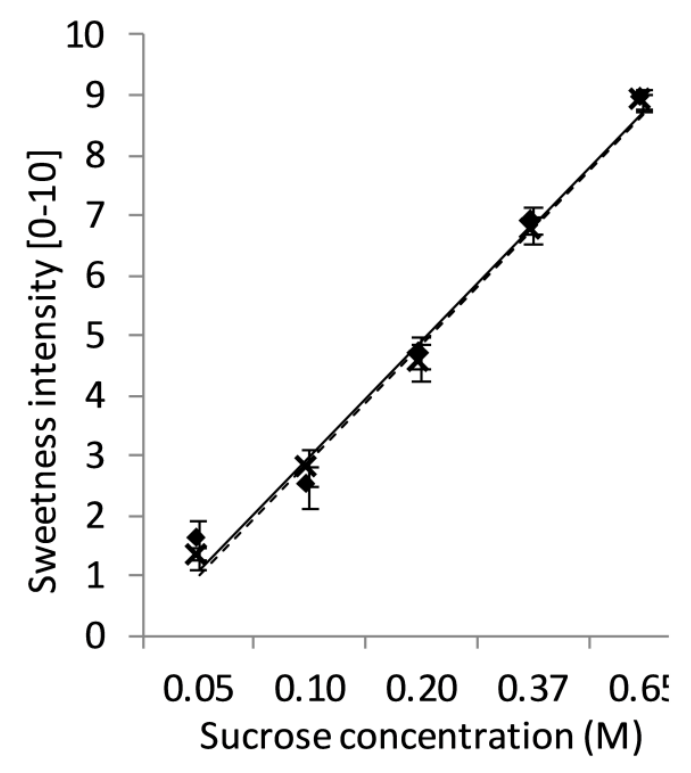

b

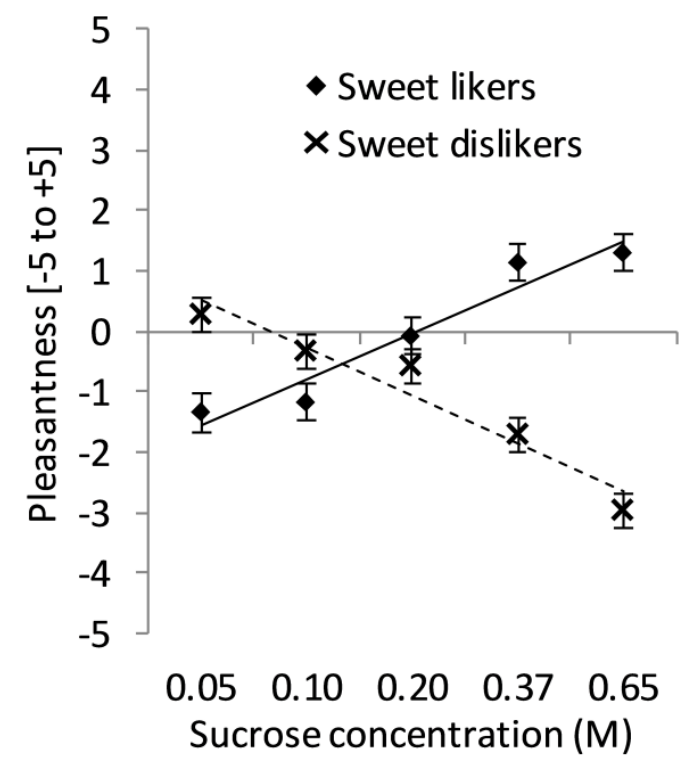

Fig. 2 Estimated means for intensity (a) and pleasantness ratings (b) by phenotype group ( $n=23$ sweet likers, $\mathrm{n}=26$ sweet dislikers) for each sucrose solution in the placebo condition. Asterisks indicate significant value for between phenotype groups contrast for each level of sucrose content. ${ }^{*} p<.05$ and $* * * p<.001$. Error bars are between-subject SEMs. Linear trend lines are added for illustrative purposes

Hedonic capacity state measure. Self-reported hedonic state capacity was measured using a modified version of the Snaith-Hamilton Pleasure Scale (SHAPS, Snaith et al. 1995) immediately after each of the four mood and subjective state measures. Two items (At this moment... "I would be able to enjoy my favorite meal" and "I would enjoy a cup of tea or coffee or my favorite drink") from this questionnaire were of particular relevance for the current study and were entered into separate analyses for investigation of MOR system effects on predicted taste reward. 
Consumption of sweet and chocolate chip cookies and salty crackers. To measure spontaneous food intake, we included a covert test of cookie consumption. At the end of each experiment session participants went through approximately 15 minutes of debriefing with the experimenter. Tea or coffee was served and participants were encouraged to help themselves to cookies from a plate. The plate contained eight medium sized chocolate chip cookies (10 gram) and 16 small salty crackers (Ritz, 4 gram) and was conveniently placed on the table next to the participant. Unbeknownst to the participant, the number and type of cookies consumed was recorded.

Plasma levels of drugs and their metabolites. Participants provided a blood sample at the end of each experiment session. Analyses were performed at The Norwegian Institute of Public Health, Division of Forensic Medicine and Drug Abuse Research, using a high-performance liquid chromatography-tandem mass spectrometry method (Karinen et al. 2009) to identify plasma levels of morphine and its two major metabolites: morphine-3-glucuronide (M3G) and morphine-6-glucuronide (M6G); and naltrexone and its major metabolite, 6- $\beta$-naltrexol (6 $\beta \mathrm{N})$.

\section{Behavioral analysis}

Repeated-measures analyses of variance (rmANOVA) were used to assess drug effects on control measures (mood, subjective state and motor coordination measures). Ratings from the three measurement points were aggregated and baseline corrected. Greenhouse-Geisser correction was employed when sphericity assumptions were violated. Any significant drug effects were controlled for in the analyses of the main outcome variables. 
Ratings of intensity, pleasantness and predicted pleasure (SHAPS) scores were analyzed with linear mixed models (LMMs) for repeated measures using the nlme package in R (Pinheiro et al. 2016) and the mixed effect model module (GENLINMIXED) in SPSS (version 22, IBM). Mixed effects models include both fixed and random effects and offer superior flexibility compared to more traditional repeated-measures analyses as they allow different target distributions and the inclusion of all data points without aggregation across multiple trials of one type, can accommodate unbalanced designs and are less sensitive to missing data points (e.g. Gueorguieva and Krystal 2004). Eighteen intensity ratings ( $0.8 \%)$ and 39 pleasantness ratings (1.8\%) were missing from the final dataset.

For intensity and pleasantness LMMs the model selection included combinations of the following fixed effects: drug (categorical), sucrose content (as an ordinal ranked variable 1-5), drug*sucrose content interaction, drug*session interaction, session number, solution order, age, genotype group, hunger and nausea ratings and body mass index (BMI, $\mathrm{kg} / \mathrm{m} 2)$. The same fixed effects were included in the predicted pleasure (SHAPS) model selections, with the exception of variables pertaining directly to the STT such as solution order and sucrose content. These models also included a fixed effect for measurement time (1, 2, 3 baseline corrected). To adjust for the dependencies in the data, a random term including intercept for subjects was added to all the LMMs. For models including information about the five levels of sucrose solutions, a random slope for sucrose content was added to the random term. The effects of group variables, phenotype (sweet liker/disliker) and genotype (AA-homozygous/G-carrier) were investigated in separate models. To analyze drug effects on the number of cookies consumed, which was characterized by a right skewed distribution typical of count data, a loglinear mixed model with a poisson distribution and log link was used. 
Model selection and evaluation. Variables relating to the experiment design and counterbalancing (such as drug, session, sucrose solution and drink order) were always kept in the LMMs. Aside from these variables we aimed for parsimonious models. The remaining covariates such as age, BMI, hunger, nausea and meaningful interactions were removed when they did not significantly affect the outcome and/or did not improve model fit. Adding a random term for subject intercept improved all LMMs as indicated by lower BICs and significant Wald Z statistics. As the correlation between sucrose content and liking scores vary between individuals and phenotype groups, all intensity and pleasantness models improved when a random slope on sucrose content was added to the random term. The Bayesian Information Criteria (BIC) was used to compare models with different fixed and random effects. Models with a smaller BIC by more than 2 were preferred. The final models selected for each analysis are described in the result section.

Standard Errors. In graphs where groups are compared (i.e. phenotype and genotype) between-subject standard error of the mean (SEMs) from the models are provided. For analyses where within-subject contrasts are of primary interest (i.e. drug contrasts) within-subject SEMs were calculated from the raw scores (Cousineau 2005).

Descriptive data. In addition to the main figures, all mean ratings per drug and condition $( \pm \mathrm{SD})$ from the STT and predicted pleasure (SHAPS questionnaire) calculated from raw scores are reported in Table 3 together with number of cookies consumed. Data are presented for the whole group and per sweet liking phenotype group. 


\section{Results}

\section{Control measures}

Subjective and mood effects

Morphine 10mg and naltrexone 50mg had minimal subjective effects compared to placebo, with mean changes from baseline for the two drug conditions differing less than 0.7 points on the 11 point VAS scale for subjective state measures. There were no significant effects of $d r u g$ on mood (feeling good, happy, irritable and anxious: all $F$ 's $<1.7$, all $p$ 's $>.2$ ). Drug condition significantly affected hunger ratings (Mean $(S E M)$ : Morphine $=2.9(0.33)$, Placebo $=3.6(0.28)$, Naltrexone $=1.99(0.42) . F_{1.7,80.9}=4.38, p=.021$, partial $\left.\eta^{2}=.084\right)$, reflecting lower hunger ratings after naltrexone than after placebo treatment. Hunger ratings for the measurement prior to the STT were therefore included as a control variable in all analyses including drug and phenotype information (but did not significantly impact intensity or pleasantness ratings in any of the models). There was also a main effect of drug on nausea ratings $(\mathrm{M}=0.54(0.17), \mathrm{P}=0.21$ (0.19), $\mathrm{N}=1.00(.32) ; F_{1.7,77.5}=3.4, p=.048$, partial $\left.\eta^{2}=.066\right)$, reflecting significantly higher nausea in the naltrexone relative to placebo conditions. Nausea was also entered into all analyses including drug and phenotype, but did not significantly affect intensity or pleasantness ratings in any of the mixed effects analyses.

Motor coordination. Dysmetria Scores did not significantly differ between drug conditions $\left(F_{2,92}=.061, p=.940\right.$, partial $\left.\eta^{2}=.001\right)$.

Drugs and metabolites in the blood. Data from blood samples drawn at the end of the test session (approximately 150 minutes after drug administration) show that all participants had 
drugs and metabolites present in the blood following administration of morphine and naltrexone (see Table 2).

Table 2 Descriptive statistics from blood analyses

\begin{tabular}{lllll}
\hline \multirow{2}{*}{ Drugs, Metabolites } & Mean & SD & Range & \\
\cline { 2 - 5 } & $(\mathrm{nmol} / \mathrm{ML})$ & & Min & $\max$ \\
\hline Morphine & 0.01017 & 0.05235 & 0.00441 & 0.02268 \\
M3G & 0.17641 & 0.01060 & 0.08513 & 0.34307 \\
M6G & 0.03528 & 0.00385 & 0.01398 & 0.06474 \\
Naltrexone & 0.01481 & 0.04671 & 0.00239 & 0.04810 \\
6BN & 0.16644 & 0.00919 & 0.10000 & 0.35529
\end{tabular}

Levels of morphine, naltrexone and major metabolites after the sweet taste task was completed, approximately 150 minutes after oral drug ingestion. M3G \& M6G = morphine-3/6-glucronide, 6BN = 6-beta-naltrexol).

\section{No effects of MOR manipulations on ratings of sweetness intensity}

The final linear mixed model (LMM) of intensity ratings included the fixed effects: $\operatorname{drug}(M, P$, $N)$, sucrose content, drug* sucrose content, genotype group (OPRM1 Al18G: AG/AA), drink order, session and session*drug interaction. As expected, we found no significant main or interaction effects of drug on intensity ratings ( $F$ 's $<1.4$, all $p$ 's $>.245$, see Fig. 3a). The effects of sucrose content and drink order were significant $(F$ 's $>20.4, p$ 's $<.001)$. Session number also significantly affected intensity ratings $\left(F_{2,2136}=4.23, p=0.15\right)$, but there was no significant drug*session interaction $\left(F_{4,2137}=1.09, p=.236\right)$. Genotype did not significantly affect intensity ratings $\left(\mathrm{F}_{2136}=0.149, \mathrm{p}=.699\right) . B M I$, age, and ratings of hunger and nausea did not contribute to the fit of the model, and did not significantly affect sweetness perception (All $F$ 's $<2.13$, all p's > .135). 
a

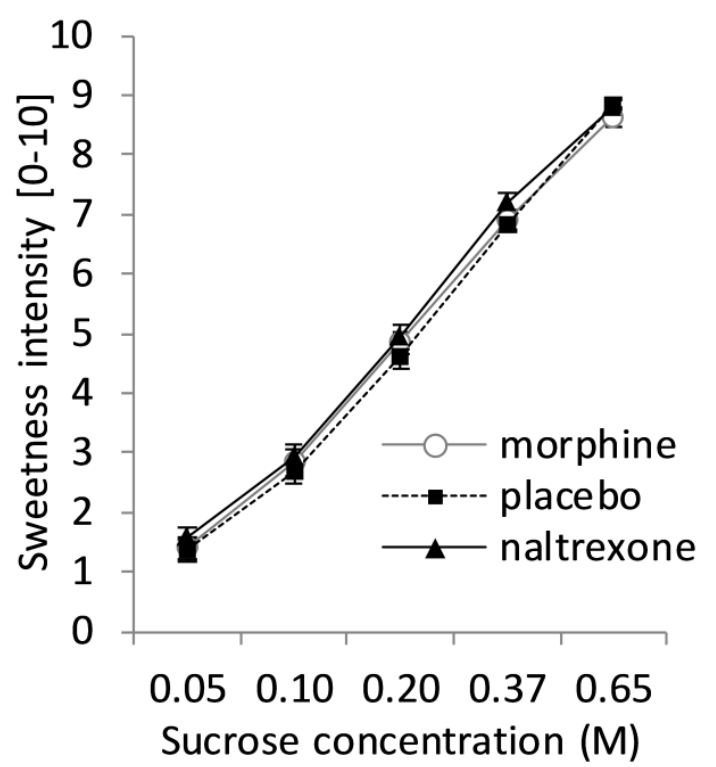

b

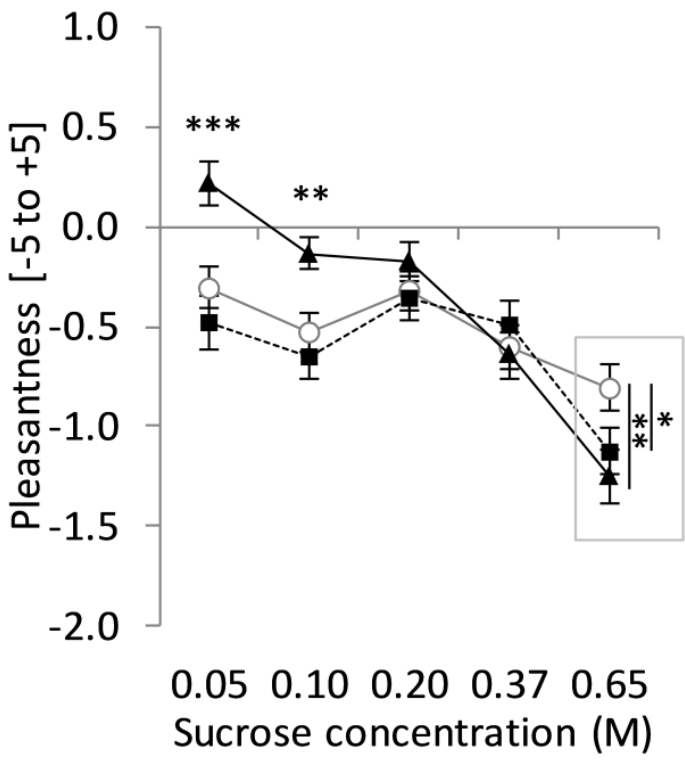

Fig. 3 a) No significant effects of drug on intensity ratings at any level of sucrose solution (in $\mathrm{MOL})$. All values are estimated means from the model. Error bars represent within-subject SEMs. b) Effects of drugs on pleasantness ratings per solution and drug. Asterisks indicate significant value for drug contrast for each level of sucrose content. * indicates $p<.05,{ }^{* *} p<.01 * * * p$ $<.001$. The primary drug contrast of interest (at $0.65 \mathrm{M}$ ) is outlined with a grey box

\section{Effects of MOR manipulations on ratings of pleasantness}

The LMM of pleasantness ratings included the fixed effects: sucrose content, drug, session drug*sucrose content, drink order and genotype group. A random subject intercept and slope on sucrose content were also included. Consistent with the main hypothesis, there was a significant interaction between the sucrose content and the drug condition $\left(F_{8,2119}=3.99, p<.001\right.$, see figure $3 b)$. Planned pair-wise comparisons showed the expected linear relationship of drugs ( $M>$ $\mathrm{P}>\mathrm{N})$ at the sweetest sucrose solution $\left(\mathrm{M}>\mathrm{N}: t_{2119}=2.8, p=.005 ; \mathrm{M}>\mathrm{P}: t_{2119}=1.99, p=.046\right.$; $\left.\mathrm{P}>\mathrm{N}: t_{2119}=0.82, p=.410\right)$. Surprisingly, ratings of the two drinks with the least sucrose were higher after naltrexone relative to both placebo and morphine conditions $(0.05 \mathrm{M}$ solution: $\mathrm{N}>\mathrm{M}$ : 
$t_{2119}=3.20, p=.001, \mathrm{~N}>\mathrm{P}: t_{2119}=4.19, p<.001 ; 0.01 \mathrm{M}$ solution: $\mathrm{N}>\mathrm{M}: t_{2119}=2.44, p=.015, \mathrm{~N}>\mathrm{P}$ : $\left.t_{2119}=3.16, p=.002\right)$. The model also revealed significant main effects of $\operatorname{drug}\left(F_{2,2119}=4.75, p\right.$ $=.009)$ and sucrose content $\left(F_{2,2119}=2.51, p=.040\right)$ as well as a significant effect of the order the drinks were presented in $\left(F_{14,2119}=7.02, p<.001\right)$. Session $\operatorname{order}\left(F_{2,2119}=0.36, p=.701\right)$ and genotype $\left(F_{2,2119}=0.735, \mathrm{p}=.391\right)$ did not significantly affect the pleasantness ratings. The effect of age, hunger, nausea and BMI did not significantly affect sucrose pleasantness ratings (All $F$ 's $<2.76$, all $p$ 's $>.095$ ) and were not included in the final model.

\section{No interaction between MOR manipulations and sweet liking phenotype}

Sweetness instensity analysis. The final intensity model included the following fixed effects: drug $(M, P, N)$, sucrose content, phenotype and all interactions between these variables, together with drink order and session. As in the above analysis of intensity ratings from the placebo session only, there was no significant main effect of phenotype $\left(F_{1,2122}=.26 p=.61\right)$. There was

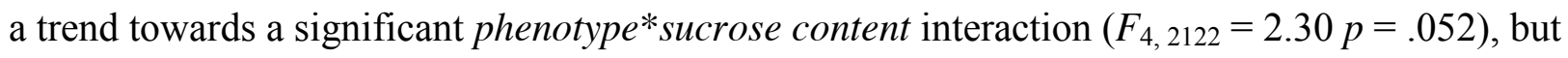
no significant three-way interaction of $d r u g *$ phenotype ${ }^{*}$ sucrose content $\left(F_{8,2122}=1.13, p=.380\right)$. The model yielded significant main effects of sucrose content $\left(F_{4,2122}=488, p<.001\right)$, drink $\operatorname{order}\left(F_{4,2122}=19.9 . p<.001\right)$ and session $\left(F_{4,2122}=4.60, p=.011\right)$, but not the session $* d r u g$ interaction $\left(F_{4,2122}=1.82, p=.121\right)$ or a main effect of $\operatorname{drug}\left(F_{2,2122}=1.36, p=.257\right)$. The remaining interactions did not significantly affect intensity ratings (all $F$ 's $<1.07$, all $p$ 's $>.38$ ).

Pleasantness analysis. The final pleasantness model including drug and phenotype information had the fixed effects $d r u g$ (excluding placebo data to avoid circularity in the analysis), sucrose content, phenotype and all interactions between these, together with drink order, session and BMI. The purpose of the analysis was to examine whether morphine and naltrexone affected pleasantness ratings differently in sweet likers and dislikers; however we observed similar drug 
effects in the two phenotype groups (Fig. 4). The three-way interaction (drug*sucrose content $*$ phenotype $)$ was not significant $\left(F_{4,1365}=0.614, p=.652\right)$ nor was the phenotype $* d r u g$ interaction $\left(F_{1,1365}=0.24, p=.625\right)$. As observed in the analysis of pleasantness ratings from the placebo condition, the effects of phenotype $\left(F_{1,1364}=16.63, p<.001\right)$ and phenotype ${ }^{*}$ sucrose content $\left(F_{4,1364}=32.70, p<.001\right)$ were significant in this model. Drink order $\left(F_{14,1364}=2.80, p\right.$ $=.024), B M I\left(F_{1,1364}=4.60, p=.032\right)$ and drug*sucrose content $\left(F_{4,1364}=5.70, p=.001\right)$ were also significant. Nausea, hunger and age did not significantly affect pleasantness ratings (all $F$ 's $<.97$, all p's $>.32$ ) and did not significantly improve the model.
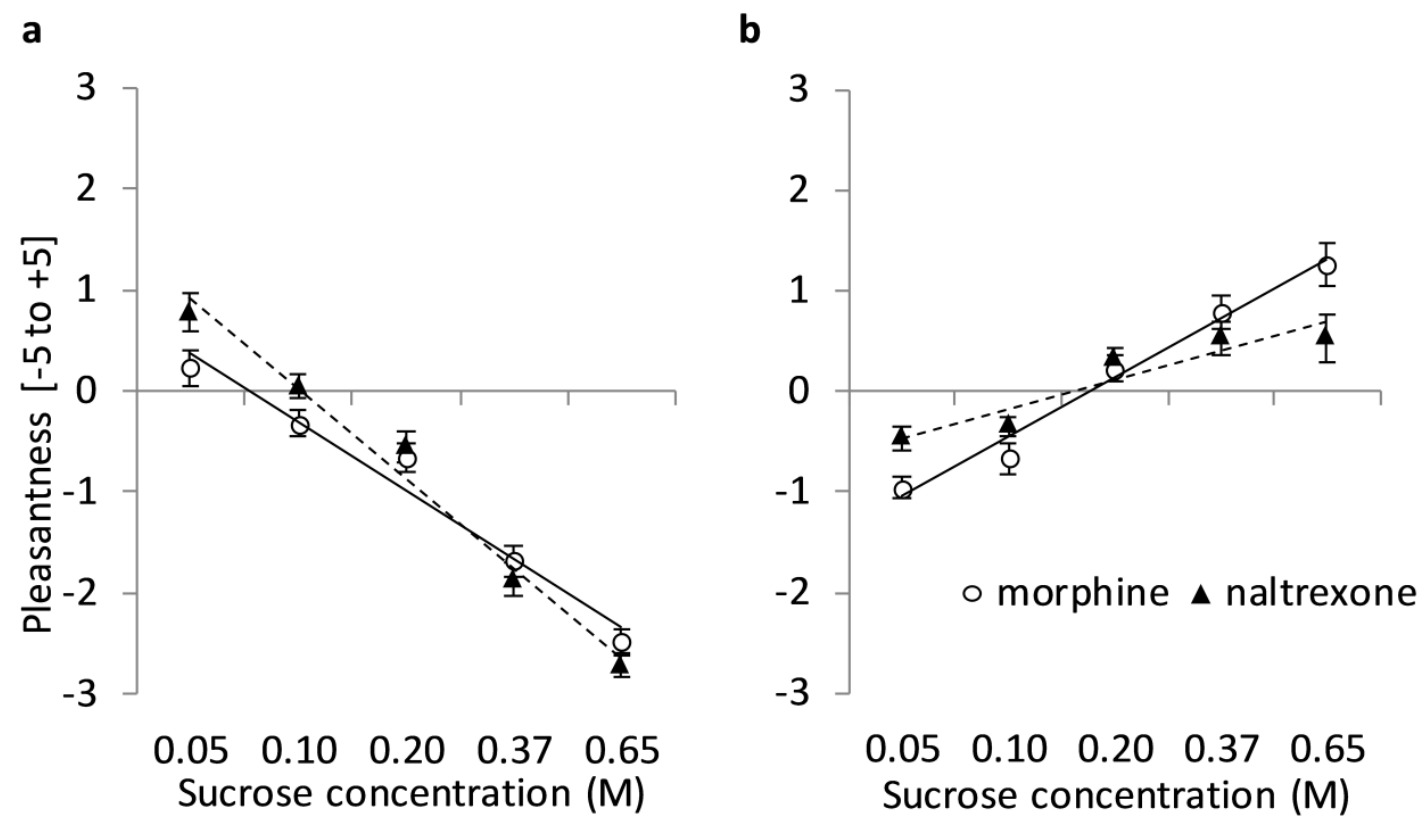

Fig. 4 Estimated means of pleasantness ratings in the morphine and naltrexone conditions reveal similar patterns of drug effects (lower correlation following naltrexone treatment than after morphine) for the two phenotype groups. A) sweet dislikers $n=26, B$ ) sweet likers $n=23$. Error bars are within-subject SEMs. Linear trend lines are added for illustrative purposes 


\section{Effects of MOR manipulations on predicted pleasure of food and drink}

There was no significant effect of drug on the overall SHAPS test score which is based on all items $\left(F_{2,425}=1.48, p=.229\right.$, see Fig. 5 and Table 3$)$.

The results from the LMM for the favorite beverage item showed a main effect of drug ( $F_{2}$, $411=6.52, p=.002$, see Fig. 5 and Table 3. Planned comparisons of drugs showed a significantly higher hedonia rating in the morphine condition compared to naltrexone $\left(t_{411}=2.86, p=.005\right)$ and a trend towards lower ratings following naltrexone compared to placebo $\left(t_{411}=1.89, p\right.$ $=.059)$. The contrast between morphine and placebo was not significant $\left(t_{411}=.93, p=.355\right)$.

The final model for favorite food item ratings also showed a significant main effect of drug $\left(F_{2,396}=4.15, p=.012\right.$; see Fig. 5 and Table 3 in the main text). Pairwise comparisons showed a significant increase in food hedonia rating with morphine over naltrexone $\left(t_{396}=2.72, p=.007\right)$ and placebo over naltrexone $\left(t_{396}=2.46, p=.014\right)$ but not with morphine compared to placebo $\left(t_{396}=.223, p=.824\right.$, see Fig. 6). The final fixed effects included in the each of the predicted pleasure (SHAPS) analyses and associated p-values are reported in Supplementary Table 1 in the SI). 

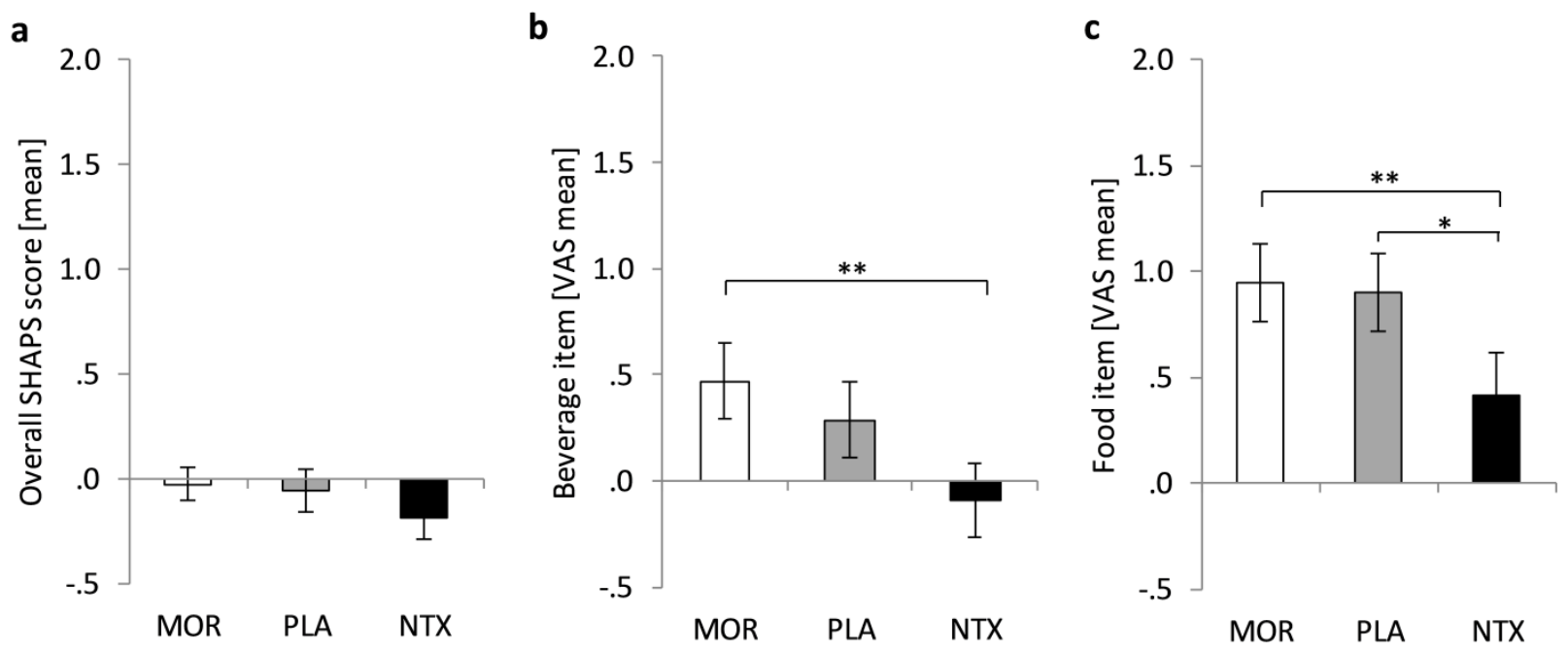

Fig. 5 Predicted pleasure (SHAPS) a) Drug effects on ratings of overall predicted pleasure ratings (average score). b) Drug effects on predicted pleasure from consuming favorite beverage. c) Drug effects on predicted pleasure from consuming favorite food. Bars show estimated means from the LMMs. MOR = morphine, PLA = placebo, NTX = naltrexone. Error bars are withinsubject SEMs. Asterisks indicate significant contrasts between drug conditions ${ }^{*} p<.05,{ }^{* *} p$ $<.01$

\section{Naltrexone reduced cookie consumption}

Number of cookies eaten was analyzed with a generalized mixed effects model with a poisson distribution and log link suited for count data (that often have a distinct right-skewed distribution). The final model of cookie data included the fixed effects: drug, type of cookie (salty, sweet), session, hunger and drug*hunger interaction. A random subject intercept was also included. The model showed a significant effect of $\operatorname{drug}\left(F_{2,273}=5.75, p=.004\right.$; Fig. 6). Planned comparisons showed that consumption of cookies was reduced after naltrexone compared to morphine (combined estimated means (SEM) for salty and sweet cookies: $\mathrm{M}=4.36(0.32), \mathrm{P}=4.21(0.31)$, $\mathrm{N}=3.84$ (0.30); contrasts: M-N: $t_{273}=2.26, p=.025 ; \mathrm{P}-\mathrm{N}: t_{273}=1.69, p=.091 ; \mathrm{M}-\mathrm{P}: t_{273}=.49, p$ $=.624)$. Participants on average consumed more salty crackers than chocolate cookies $\left(F_{2,273}=\right.$ 
$24.2, p>.001)$ but there was no significant cookie type* drug interaction $\left(F_{2,255}=.032, p=.969\right)$. Further, the main effect of hunger on cookie consumption was not significant $\left(F_{2,273}=1.86, p\right.$ $=.174)$ but a significant drug*hunger interaction effect $\left(F_{2,273}=3.33, p=.037\right)$ reflected a larger reduction in cookie consumption after naltrexone treatment when hunger reports were low. Session order significantly affected cookie consumption due to higher consumption in the last session $\left(F_{2,273}=9.78, p<.001\right)$ but the session $*$ drug interaction was not significant $\left(F_{2,273}=1.98\right.$, $p=.099)$. Age, phenotype, genotype, BMI and nausea did not significantly affect number of cookies eaten (all $F$ 's $<2.36, p$ 's $>.126$ ).

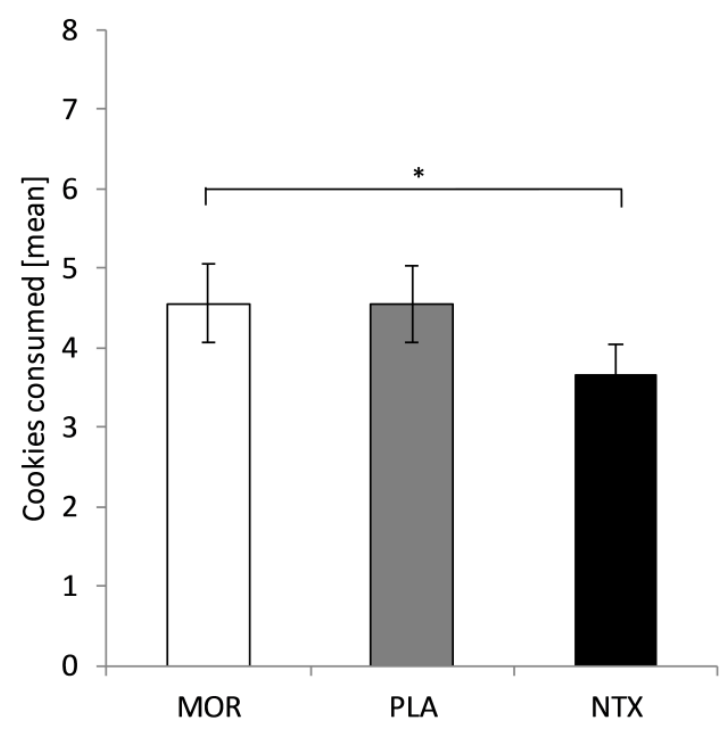

Fig. 6 Naltrexone reduced the number of cookies consumed in the covert cookie test administered during debriefing. Bars show combined estimated means for the two types of cookies from the mixed model. Asterisks indicate significant contrasts between drug conditions $* p<.05$. Error bars represent within-subject SEMs 
Table 3. Means (SD) from the STT, SHAPS and cookie test by drug, overall and by phenotype group.

\begin{tabular}{|c|c|c|c|c|c|c|c|c|c|}
\hline \multirow[b]{2}{*}{ Sucrose Content } & \multicolumn{3}{|c|}{ Overall $(n=49)$} & \multicolumn{3}{|c|}{ Likers $(n=23)$} & \multicolumn{3}{|c|}{ Dislikers $(n=26)$} \\
\hline & MOR & PLA & NTX & MOR & PLA & NTX & MOR & PLA & NTX \\
\hline \multicolumn{10}{|c|}{ Pleasantness rating (-5 to 5$)$} \\
\hline $0.05 \mathrm{M}$ & $-0.4(1.7)$ & $-0.5(1.6)$ & $0.1(1.5)$ & $-1.1(1.7)$ & $-1.4(1.5)$ & $-0.7(1.0)$ & $0.2(1.3)$ & $0.2(1.4)$ & $0.9(1.5)$ \\
\hline $0.1 \mathrm{M}$ & $-0.5(1.3)$ & $-0.6(1.3)$ & $0.0(1.0)$ & $-0.6(1.2)$ & $-1.1(1.3)$ & $-0.4(0.8)$ & $-0.3(1.0)$ & $-0.1(1.1)$ & $0.3(1.1)$ \\
\hline $0.2 \mathrm{M}$ & $-0.21(1.0)$ & $-0.3(1.4)$ & $-0.1(1.1)$ & $0.1(1.3)$ & $0.1(1.3)$ & $0.4(1.1)$ & $-0.7(1.1)$ & $-0.7(1.4)$ & $-0.5(0.8)$ \\
\hline $0.36 \mathrm{M}$ & $-0.45(1.1)$ & $-0.4(2.0)$ & $-0.6(2.0)$ & $0.8(2.1)$ & $1.1(1.3)$ & $0.8(1.6)$ & $-1.8(1.6)$ & $-1.9(1.1)$ & $-1.8(1.4)$ \\
\hline $0.65 \mathrm{M}$ & $-0.61(1.6)$ & $-1.2(2.8)$ & $-1.3(2.6)$ & $1.3(2.7)$ & $1.2(2.1)$ & $0.3(2.5)$ & $-2.6(2.2)$ & $-3.3(1.3)$ & $-2.9(1.6)$ \\
\hline \multicolumn{10}{|c|}{ Sweetness rating $(0-10)$} \\
\hline $0.05 \mathrm{M}$ & $1.5(1.6)$ & $1.1(1.3)$ & $1.1(1.3)$ & $1.6(1.7)$ & $1.3(1.5)$ & $1.3(1.3)$ & $1.5(1.5)$ & $0.9(1.1)$ & $1.3(1.5)$ \\
\hline $0.1 \mathrm{M}$ & $2.8(1.8)$ & $2.6(1.6)$ & $2.4(1.5)$ & $2.6(1.5)$ & $2.3(1.6)$ & $2.5(1.7)$ & $2.9(2.0)$ & $2.0(1.4)$ & $2.8(1.5$ \\
\hline $0.2 \mathrm{M}$ & $5.0(1.2)$ & $4.7(1.2)$ & $4.7(1.5)$ & $4.9(1.2)$ & $4.7(1.3)$ & $5.1(1.6)$ & $4.9(1.3)$ & $4.7(1.8)$ & $5.0(1.4)$ \\
\hline $0.36 \mathrm{M}$ & $7.1(1.3)$ & $7.1(1.0)$ & $7.1(1.1)$ & $6.8(1.1)$ & $7.2(1.0)$ & $7.5(1.3)$ & $7.3(1.5)$ & $7.1(1.2)$ & $7.4(1.3)$ \\
\hline $0.65 \mathrm{M}$ & $8.4(1.8)$ & $8.9(0.7)$ & $9.0(0.7)$ & $8.4(1.6)$ & $9.0(0.7)$ & $8.8(1.1)$ & $8.2(1.9)$ & $8.9(0.7)$ & $8.9(0.8)$ \\
\hline
\end{tabular}

SHAPS drug change from baseline, overall score and select items

\begin{tabular}{|c|c|c|c|c|c|c|c|c|c|}
\hline SHAPS score & $-0.01(0.7)$ & $-0.1(0.8)$ & $-0.2(1.0)$ & $-0.1(0.8)$ & $-0.2(0.9)$ & $-0.2(0.7)$ & $0.1(0.8)$ & $0.0(0.9)$ & $-0.3(0.7)$ \\
\hline Favorite beverage & $0.5(1.5)$ & $0.3(1.3)$ & $-0.1(1.7)$ & $0.3(1.4)$ & $0.3(1.4)$ & $-0.1(1.1)$ & $0.6(1.4)$ & $0.4(1.4)$ & $-0.2(1.1)$ \\
\hline Favorite food & $1.0(1.4)$ & $0.8(1.5)$ & $0.4(1.9)$ & $1.2(1.8)$ & $0.5(1.4)$ & $0.6(1.8)$ & $0.8(1.7)$ & $1.2(1.4)$ & $0.2(1.8)$ \\
\hline \multicolumn{10}{|c|}{ verage cookie consumption $N(S D)$} \\
\hline Chocolate chip & $4.5(2.0)$ & $2.2(1.7)$ & $1.8(1.5)$ & $2.4(2.2)$ & $2.3(1.7)$ & $1.7(1.6)$ & $2.1(1.7)$ & $2.1(1.6)$ & $1.9(1.3)$ \\
\hline Salty Crackers & $3.4(4.3)$ & $3.4(4.3)$ & $2.8(3.8)$ & $4.7(5.1)$ & $4.7(5.1)$ & $3.0(3.7)$ & $2.2(3.0)$ & $2.2(3.0)$ & $2.5(3.9)$ \\
\hline Overall & $7.9(3.4)$ & $5.7(3.3)$ & $4.5(2.9)$ & $7.1(4.0)$ & $7.0(3.9)$ & $4.7(2.9)$ & $4.2(2.5)$ & $4.2(2.4)$ & $4.3(2.9)$ \\
\hline
\end{tabular}

Means per condition/drug/group and standard deviations are calculated from raw data. 


\section{Discussion}

Stimulation of the $\mu$-opioid receptor in healthy humans with morphine increased reported pleasantness of the sweetest of five sucrose-water solutions, without enhancing pleasantness of the solutions with less sucrose. For opioid antagonism with naltrexone, an opposite pattern was observed for the sweetest drink only. This bidirectional effect of opioid agonist and antagonist treatment is consistent with rodent research showing the strongest effects of MOR manipulations for the most palatable foods. Importantly, the observed drug effect on liking of the sweetest drink did not differ between sweet likers and sweet dislikers. Since dislikers found the high-sucrose drink aversive, we interpret this finding as evidence that the endogenous $\mu$-opioid system preferentially regulates behaviors associated with high objective (caloric) value.

Despite extensive rodent evidence that endogenous release and exogenous MOR stimulation is associated with increased intake and 'liking' of palatable foods such as sucrose (Berridge 2009; Evans and Vaccarino 1990; Peciña et al. 2006), the question of whether MOR agonism similarly increases sweet taste liking in humans had not been resolved until now. To our knowledge, only two previous studies have assessed effects of MOR agonism on sweet taste intake and/or liking in humans (Drewnowski et al. 1992; Morley et al. 1985). These studies used butorphanol, which acts as both agonist and antagonist at the receptor; interpretation of their (opposing) results is further complicated by small sample sizes. Our design allowed a demonstration of morphineenhanced pleasantness of the sweetest drink without confounding drug effects on e.g. intensity perception, mood or motor coordination. Indeed, subjective drug effects were so minimal that participants were unable to distinguish active drug from placebo sessions.

Our design also enabled us to confirm that MOR agonism and antagonism yielded opposite changes in liking, as demonstrated by the linear contrast morphine>placebo>naltrexone $\left(\begin{array}{lll}1 & 0 & -1\end{array}\right)$ for the sweetest drink. This finding aligns well with an extensive rodent literature demonstrating 
MOR effects on high calorie foods. For instance, Taha and colleagues (2006) observed that systemic naltrexone selectively reduced consumption of the sweetest sucrose solution available. Intake of a $4 \%$ solution was decreased when the alternative drink was sugar-free, but not when the alternative was $20 \%$ sucrose. Parallel effects have been shown for other palatable foods and even for other types of reinforcing stimuli. MOR stimulation increased preference for chocolate and high-value potential sexual partners (i.e. estrous female rats) compared to normal chow and non-fertile female rats (Mahler and Berridge 2012). Opioid antagonism has also been shown to more potently reduce intake of preferred chocolate chip cookies over normal chow (Giraudo et al. 1993). In humans, we previously reported an analogous effect in a facial attractiveness task (Chelnokova et al. 2014). In a subset of the present study population, morphine and naltrexone specifically modulated preference for a human analogue of high-value potential sexual partners, i.e. the most attractive female faces.

A unique feature of the present design is the use of a high objective (caloric) value stimulus that is not the preferred stimulus for the majority of the study population (53\% were sweet dislikers). Thus, we were able to ask whether the human MOR system specifically modulates liking of stimuli with the highest subjective or the highest objective value. The similarity of drug effects on the sweetest sucrose solution in sweet likers and dislikers (increased pleasantness and reduced unpleasantness) suggest that the MOR system most strongly affects liking of evolutionarily useful stimuli. Since the pattern of results was apparent even in dislikers who found the sweetest drink aversive, the association between the MOR system and hedonic eating appears to be independent of initial personal preference. Support for this notion also comes from an analogous study of rats bred for high and low sucrose preference (Gosnell et al. 2010). We speculate that the MOR system promotes concordance between the subjective and the objective value of potential rewards in the environment. 
Ratings of predicted pleasure of palatable (favorite) foods and drink showed a similar bidirectional pattern after MOR manipulations. No significant drug effects were found when all food and non-food items of the predicted pleasure scale were included, however. The covert cookie consumption test administered at the end of each session revealed that naltrexone significantly reduced the number of cookies eaten, consistent with numerous previous reports on the effects of acute MOR antagonism (Bertino et al. 1991; Levine et al. 2003; Trenchard and Silverstone 1983; Yeomans and Gray 1997; Yeomans and Wright 1991; Ziauddeen et al. 2013). The lack of a bidirectional effect on cookie consumption is difficult to interpret, as this test was conducted long after morphine was expected to reach peak concentration. Whether different test timing or a higher dose of either drug would yield stronger effects remains to be determined.

Unexpectedly, naltrexone also significantly increased pleasantness ratings of the two lowest sucrose solutions. A previous study which administered a similar sweet taste test in healthy women reported a main effect such that naltrexone reduced pleasantness ratings across sucrose solutions (Arbisi et al. 1999). Since morphine did not oppositely affect pleasantness of the lowsucrose drinks, we speculate that the increased liking could be driven by non-MOR effects of naltrexone, such as antagonism of kappa opioid receptors (McLeod et al. 2001) Note that the slight decrease in hunger and increase in nausea scores induced by naltrexone did not affect the pattern of results reported in this study. In an effort to avoid potential drug interaction with circulating levels of estradiol and GnRH pulsability in females (Smith et al. 1998) only male participants were included in the test sample. Existing studies of taste using opioid antagonists only have yielded no consistent indications that opioids affect taste evaluations differently in men and women (see e.g. Drewnowski et al. 1992; MacIntosh et al. 2001). Since the current hypotheses are based on cross-species evidence consistent with an evolutionarily preserved 
function of MOR, we predict that future studies will reveal similar effects in women as the ones presented here for men.

Sweet taste responses are thought to be partly genetically determined (Keskitalo et al. 2007). Polymorphisms of the MOR gene OPRM1 contribute to natural variation in central MOR system function across individuals and species (Mague and Blendy 2010). Although findings are inconsistent, presence of one or more $\mathrm{G}$ alleles of the functional single-nucleotide polymorphism (SNP) A118G has been associated with increased liking of cocaine (Dlugos et al. 2011) and alcohol (Ray and Hutchison 2004), as well as altered pain perception (Olsen et al. 2012b; Peciña et al. 2015). The A118G SNP also explained some variability in responses to MOR antagonists and agonists (e.g. Anton et al. 2008; Chidambaran et al. 2015). In the current study, we oversampled $\mathrm{G}$ carriers to examine interactions between this OPRM1 polymorphism and MOR drug manipulations on sweet taste perception. We did not however find significant main effects or interactions on any measures. This may be a false negative due to low statistical power of our candidate gene approach. Although the A118G SNP has been associated with a range of behaviors relevant to opioid receptor functions, several reviews, meta-analyses and original articles have failed to replicate published results (e.g. Franke et al. 2001; Mague and Blendy 2010).

The prevalence of healthy people showing a strong sweet disliking profile means that on a group level, pleasantness ratings of sucrose-water solutions are seldom highly positive (Methven et al. 2016; Weafer et al. 2014). Pleasantness evaluations of sucrose-water nevertheless correlate closely with ratings of similarly sweet flavored drinks (Looy et al. 1992). The sweet liking phenotype appears to be more common in groups with drug addiction or family history of drug addiction (e.g. see Janowsky et al. 2003; Kampov-Polevoy et al. 1997; Wronski et al. 2007). 
Preference for sweet foods has been positively correlated with excess body weight (Berthoud and Zheng 2012), while others find no such effect (Bellisle 2010). Obesity and poor eating habits are common in patient groups where MOR system function is known to be disrupted, such as in chronic pain and drug use disorder (Leknes and Bastian 2014). A recent study demonstrated a MOR dysfunction in morbid obesity, which was normalized after bariatric surgery (Karlsson et al. 2015). Chronic opioid use (both maintenance treatment and abuse) is associated with increased craving for and intake of palatable sugary foods and drink (e.g. Mysels and Sullivan 2010; Neale et al. 2012; Nolan and Scagnelli 2007).The reduced liking and intake of high-calorie foods reported here and elsewhere after acute MOR antagonism may nevertheless have limited implications for clinical groups and treatments. For instance, whereas acute treatment with a specific MOR antagonist reduced food liking (Nathan et al. 2012), a one-month treatment trial in overweight individuals resulted in moderate weight gain in most participants (Ziauddeen et al. 2013).

Here, we demonstrate increased liking of the highest-sucrose solution following stimulation of the $\mu$-opioid receptor with a non-sedative dose of morphine. Overall, the bidirectional effects of MOR agonism and antagonism reported here support the hypothesis that the endogenous MOR system encodes liking of high-calorie foods in humans. Our findings align well with an extensive rodent literature demonstrating MOR effects on calorie rich foods, and a series of studies implicating opioids in feeding behavior across the evolutionary chain - in amoebas, mollusks, birds and mammals (Morley 1995). Interestingly, we find no evidence that the effects of MOR manipulations differ between sweet likers and dislikers, even though sweet dislikers find the sweetest drink aversive. We therefore speculate the $\mu$-opioid receptor system promotes survival in part by increasing concordance between the objective (caloric) and subjective (hedonic) value of food stimuli, so that feeding behavior becomes more focused on the richest food available. 


\section{References}

Anton RF, Oroszi G, O’Malley S, Couper D, Swift R, Pettinati H, Goldman D (2008) An evaluation of $\mu$-opioid receptor (OPRM1) as a predictor of naltrexone response in the treatment of alcohol dependence: results from the Combined Pharmacotherapies and Behavioral Interventions for Alcohol Dependence (COMBINE) study. Arch Gen Psychiatry 65: 135-144.

Arbisi P, Billington C, Levine A (1999) The effect of naltrexone on taste detection and recognition threshold. Appetite 32: 241-249.

Asao K, Miller J, Arcori L, Lumeng JC, Han-Markey T, Herman WH (2015) Patterns of Sweet Taste Liking: A Pilot Study. Nutrients 7: 7298-7311.

Bellisle F (2010) Ingestive behaviours and sugar. Comportement alimentaire et sucre 4: 511-513.

Berman AH, Bergman H, Palmstierna T, Schlyter F (2005) Evaluation of the Drug Use Disorders Identification Test (DUDIT) in criminal justice and detoxification settings and in a Swedish population sample. Eur Addict Res 11: 22-31.

Berridge KC (2000) Measuring hedonic impact in animals and infants: microstructure of affective taste reactivity patterns. Neuroscience \&amp; Biobehavioral Reviews 24: 173-198.

Berridge KC (2009) Wanting and liking: Observations from the neuroscience and psychology laboratory. Inquiry 52: 378-398.

Berridge KC, Kringelbach ML (2008) Affective neuroscience of pleasure: Reward in humans and animals. Psychopharmacology (Berl) 199: 457-480.

Berthoud HR, Zheng H (2012) Modulation of taste responsiveness and food preference by obesity and weight loss. Physiol Behav 107: 527-532.

Bertino M, Beauchamp GK, Engelman K (1991) Naltrexone, an opioid blocker, alters taste perception and nutrient intake in humans. American Journal of Physiology-Regulatory, Integrative and Comparative Physiology 261: R59-R63.

Chelnokova O, Laeng B, Eikemo M, Riegels J, Løseth G, Maurud H, Willoch F, Leknes S (2014) Rewards of beauty: the opioid system mediates social motivation in humans. Mol Psychiatry.

Chidambaran V, Mavi J, Esslinger H, Pilipenko V, Martin LJ, Zhang K, Sadhasivam S (2015) Association of OPRM1 A118G variant with risk of morphine-induced respiratory depression following spine fusion in adolescents. Pharmacogenomics J 15: 255-262.

Cleary J, Weldon DT, O'Hare E, Billington C, Levine AS (1996) Naloxone effects on sucrosemotivated behavior. Psychopharmacology (Berl) 126: 110-114.

Cousineau D (2005) Confidence intervals in within-subject designs: A simpler solution to Loftus and Masson's method. Tutorials in quantitative methods for psychology 1: 42-45.

DiFeliceantonio Alexandra G, Mabrouk Omar S, Kennedy Robert T, Berridge Kent C (2012) Enkephalin Surges in Dorsal Neostriatum as a Signal to Eat. Curr Biol 22: 1918-1924.

Dlugos AM, Hamidovic A, Hodgkinson C, Shen PH, Goldman D, Palmer AA, De Wit H (2011) OPRM1 gene variants modulate amphetamine-induced euphoria in humans. Genes, Brain and Behavior 10: 199-209.

Doyle TG, Berridge KC, Gosnell BA (1993) Morphine enhances hedonic taste palatability in rats. Pharmacology Biochemistry and Behavior 46: 745-749. 
Drewnowski A, Krahn DD, Demitrack MA, Nairn K, Gosnell BA (1992) Taste responses and preferences for sweet high-fat foods: Evidence for opioid involvement. Physiol Behav 51: 371-379.

Evans KR, Vaccarino FJ (1990) Amphetamine-and morphine-induced feeding: evidence for involvement of reward mechanisms. Neurosci Biobehav Rev 14: 9-22.

Franke P, Wang T, Nöthen MM, Knapp M, Neidt H, Albrecht S, Jahnes E, Propping P, Maier W (2001) Nonreplication of association between $\mu$ - opioid - receptor gene (OPRM1) A118G polymorphism and substance dependence. Am J Med Genet 105: 114-119.

Giovannoni G, Van Schalkwyk J, Fritz VU, Lees AJ (1999) Bradykinesia akinesia incoordination test (BRAIN TEST): An objective computerised assessment of upper limb motor function. J Neurol Neurosurg Psychiatry 67: 624-629.

Giraudo SQ, Grace MK, Welch CC, Billington CJ, Levine AS (1993) Naloxone's anorectic effect is dependant upon the relative palatability of food. Pharmacology Biochemistry and Behavior 46: 917-921.

Gosnell BA, Mitra A, Avant RA, Anker JJ, Carroll ME, Levine AS (2010) Operant responding for sucrose by rats bred for high or low saccharin consumption. Physiol Behav 99: 529533.

Gueorguieva R, Krystal JH (2004) Move over anova: Progress in analyzing repeated-measures data andits reflection in papers published in the archives of general psychiatry. Arch Gen Psychiatry 61: 310-317.

Hetherington MM, Vervaet N, Blass E, Rolls BJ (1991) Failure of naltrexone to affect the pleasantness or intake of food. Pharmacology Biochemistry and Behavior 40: 185-190.

Janowsky DS, Pucilowski O, Buyinza M (2003) Preference for higher sucrose concentrations in cocaine abusing-dependent patients. J Psychiatr Res 37: 35-41.

Kampov-Polevoy A, Lange L, Bobashev G, Eggleston B, Root T, Garbutt JC (2014) Sweet-liking is associated with transformation of heavy drinking into alcohol-related problems in young adults with high novelty seeking. Alcoholism: Clinical and Experimental Research 38: 2119-2126.

Kampov-Polevoy AB, Garbutt JC, Janowsky D (1997) Evidence of preference for a highconcentration sucrose solution in alcoholic men. Am J Psychiatry 154: 269-70.

Karinen R, Andersen JM, Ripel Å, Hasvold I, Hopen AB, Mørland J, Christophersen AS (2009) Determination of Heroin and Its Main Metabolites in Small Sample Volumes of Whole Blood and Brain Tissue by Reversed-Phase Liquid Chromatography-Tandem Mass Spectrometry. J Anal Toxicol 33: 345-350.

Karlsson HK, Tuulari JJ, Tuominen L, Hirvonen J, Honka H, Parkkola R, Helin S, Salminen P, Nuutila P, Nummenmaa L (2015) Weight loss after bariatric surgery normalizes brain opioid receptors in morbid obesity. Mol Psychiatry.

Keskitalo K, Knaapila A, Kallela M, Palotie A, Wessman M, Sammalisto S, Peltonen L, Tuorila H, Perola M (2007) Sweet taste preferences are partly genetically determined: Identification of a trait locus on chromosome 16. Am J Clin Nutr 86: 55-63.

Lee MC, Wagner Jr HN, Tanada S, Frost JJ, Bice AN, Dannals DF (1988) Duration of occupancy of opiate receptors by naltrexone. J Nucl Med 29: 1207-1211.

Leknes S, Bastian B (2014) How does pain affect eating and food pleasure? Pain 155: 652-653.

Levine AS, Kotz CM, Gosnell BA (2003) Sugars and fats: The neurobiology of preference. J Nutr 133: 831S-834S.

Looy H, Callaghan S, Weingarten HP (1992) Hedonic response of sucrose likers and dislikers to other gustatory stimuli. Physiol Behav 52: 219-225. 
Lugo RA, Kern SE (2002) Clinical pharmacokinetics of morphine. Journal of Pain and Palliative Care Pharmacotherapy 16: 5-18.

MacIntosh CG, Sheehan J, Davani N, Morley JE, Horowitz M, Chapman IM (2001) Effects of Aging on the Opioid Modulation of Feeding in Humans. J Am Geriatr Soc 49: 1518-1524.

Mague SD, Blendy JA (2010) OPRM1 SNP (A118G): Involvement in disease development, treatment response, and animal models. Drug Alcohol Depend 108: 172-182.

Mahler SV, Berridge KC (2012) What and when to "want"? Amygdala-based focusing of incentive salience upon sugar and sex. Psychopharmacology (Berl) 221: 407-426.

McLeod RL, Parra LE, Mutter JC, Erickson CH, Carey GJ, Tulshian DB, Fawzi AB, Smith Torhan A, Egan RW, Cuss FM (2001) Nociceptin inhibits cough in the guinea - pig by activation of ORL1 receptors. Br J Pharmacol 132: 1175-1178.

Methven L, Xiao C, Cai M, Prescott J (2016) Rejection thresholds (RjT) of sweet likers and dislikers. Food Quality and Preference 52: 74-80.

Miotto K, McCann M, Basch J, Rawson R, Ling W (2002) Naltrexone and dysphoria: Fact or myth? Am J Addict 11: 151-160.

Morley JE (1995) The role of peptides in appetite regulation across species. Am Zool 35: 437445.

Morley JE, Parker S, Levine AS (1985) Effect of butorphanol tartrate on food and water consumption in humans. The American journal of clinical nutrition 42: 1175-1178.

Mysels DJ, Sullivan MA (2010) The relationship between opioid and sugar intake: Review of evidence and clinical applications. Journal of Opioid Management 6: 445-452.

Nathan PJ, O'Neill BV, Bush MA, Koch A, Tao WX, Maltby K, Napolitano A, Brooke AC, Skeggs AL, Herman CS, Larkin AL, Ignar DM, Richards DB, Williams PM, Bullmore ET (2012) Opioid receptor modulation of hedonic taste preference and food intake: A singledose safety, pharmacokinetic, and pharmacodynamic investigation with GSK1521498, a novel $\mu$-opioid receptor inverse agonist. J Clin Pharmacol 52: 464-474.

Neale J, Nettleton S, Pickering L, Fischer J (2012) Eating patterns among heroin users: a qualitative study with implications for nutritional interventions. Addiction 107: 635-641.

Nolan LJ, Scagnelli LM (2007) Preference for sweet foods and higher body mass index in patients being treated in long-term methadone maintenance. Subst Use Misuse 42: 15551566.

Olsen MB, Jacobsen LM, Schistad EI, Pedersen LM, Rygh LJ, Roe C, Gjerstad J (2012a) Pain Intensity the First Year after Lumbar Disc Herniation Is Associated with the A118G Polymorphism in the Opioid Receptor Mu 1 Gene: Evidence of a Sex and Genotype Interaction. J Neurosci 32: 9831-4.

Olsen MB, Jacobsen LM, Schistad EI, Pedersen LM, Rygh LJ, Røe C, Gjerstad J (2012b) Pain intensity the first year after lumbar disc herniation is associated with the A118G polymorphism in the opioid receptor mu 1 gene: Evidence of a sex and genotype interaction. J Neurosci 32: 9831-9834.

Peciña M, Love T, Stohler CS, Goldman D, Zubieta J-K (2015) Effects of the mu opioid receptor polymorphism (OPRM1 A118G) on pain regulation, placebo effects and associated personality trait measures. Neuropsychopharmacology 40: 957-965.

Peciña S, Smith KS, Berridge KC (2006) Hedonic hot spots in the brain. Neuroscientist 12: 500511.

Pinheiro J, Bates D, DebRoy S, Sarkar D, R Core Team ( 2016) nlme: Linear and Nonlinear Mixed Effects Model 
Ray LA, Hutchison KE (2004) A Polymorphism of the-Opioid Receptor Gene (OPRM1) and Sensitivity to the Effects of Alcohol in Humans. Alcoholism-Clinical and Experimental Research 28: 1789-1795.

Saunders JB, Aasland OG, Babor TF, De La Fuente JR, Grant M (1993) Development of the Alcohol Use Disorders Identification Test (AUDIT): WHO Collaborative Project on Early Detection of Persons with Harmful Alcohol Consumption-II. Addiction 88: 791-804.

Scinska A, Koro E, Polanowska E, Kukwa A, Bogucka-Bonikowska A, Kostowski W, Habrat B, Bienkowski P (2000) An opioid receptor antagonist, naltrexone, does not alter taste and smell responses in humans. Pharmacol Rep 52: 397-402.

Smith YR, Zubieta J-K, Carmen MGd, Dannals RF, Ravert HT, Zacur HA, Frost JJ (1998) Brain Opioid Receptor Measurements by Positron Emission Tomography in Normal Cycling Women: Relationship to Luteinizing Hormone Pulsatility and Gonadal Steroid Hormones. The Journal of Clinical Endocrinology \& Metabolism 83: 4498-4505.

Snaith RP, Hamilton M, Morley S, Humayan A, Hargreaves D, Trigwell P (1995) A scale for the assessment of hedonic tone. The Snaith-Hamilton Pleasure Scale. Br J Psychiatry 167: 99103.

Taha SA, Norsted E, Lee LS, Lang PD, Lee BS, Woolley JD, Fields HL (2006) Endogenous opioids encode relative taste preference. Eur J Neurosci 24: 1220-1226.

Trenchard E, Silverstone T (1983) Naloxone reduces the food intake of normal human volunteers. Appetite 4: 43-50.

Verebey K, Volavka J, Mule SJ, Resnick RB (1976) Naltrexone: Disposition, metabolism and effects after acute and chronic dosing. Clin Pharmacol Ther 20: 315-328.

Vindenes V, Handal M, Ripel Å, Boix F, Mørland J (2006) Conditioned place preference induced by morphine and morphine-6-glucuronide in mice. Pharmacology Biochemistry and Behavior 85: 292-297.

Weafer J, Burkhardt A, de Wit H (2014) Sweet taste liking is associated with impulsive behaviors in humans. Front Behav Neurosci 8.

Wronski M, Skrok-Wolska D, Samochowiec J, Ziolkowski M, Swiecicki L, Bienkowski P, Korkosz A, Zatorski P, Kukwa W, Scinska A (2007) Perceived intensity and pleasantness of sucrose taste in male alcoholics. Alcohol Alcohol 42: 75-79.

Yeomans MR, Gray RW (1996) Selective effects of naltrexone on food pleasantness and intake. Physiol Behav 60: 439-446.

Yeomans MR, Gray RW (1997) Effects of naltrexone on food intake and changes in subjective appetite during eating: Evidence for opioid involvement in the appetizer effect. Physiol Behav 62: 15-21.

Yeomans MR, Gray RW (2002) Opioid peptides and the control of human ingestive behaviour. Neurosci Biobehav Rev 26: 713-728.

Yeomans MR, Wright P (1991) Lower pleasantness of palatable foods in nalmefene-treated human volunteers. Appetite 16: 249-259.

Ziauddeen H, Chamberlain SR, Nathan PJ, Koch A, Maltby K, Bush M, Tao WX, Napolitano A, Skeggs AL, Brooke AC, Cheke L, Clayton NS, Sadaf Farooqi I, O'Rahilly S, Waterworth D, Song K, Hosking L, Richards DB, Fletcher PC, Bullmore ET (2013) Effects of the muopioid receptor antagonist GSK1521498 on hedonic and consummatory eating behaviour: A proof of mechanism study in binge-eating obese subjects. Mol Psychiatry 18: 12871293. 


\section{Supplementary Material for}

\section{Sweet taste pleasantness is modulated by morphine and naltrexone}

Marie Eikemo*, Guro E. Løseth, Tom Johnstone, Johannes Gjerstad, Frode Willoch, Siri Leknes

*Correspondence should be addressed to Marie Eikemo: m.h.eikemo@medisin.uio.no

\section{This file contains:}

Supplementary analysis and results

1. Sweet liking phenotype placebo data analyses

2. Analysis of OPRM1 A118G polymorphism

3. Details and statistics for predicted pleasure (SHAPS) analysis 


\section{Sweet Liking Phenotype Analyses}

Linear mixed models (LMMs) of intensity and pleasantness ratings from the placebo session only were conducted to assess potential differences between phenotype groups on intensity perception and overall pleasantness scores.

The final LMMs for intensity and pleasantness ratings from the placebo condition included the fixed effects: sucrose content, phenotype, phenotype*sucrose content, drink order and session. As expected, intensity ratings were significantly affected by sucrose content $\left(F_{1,705}=274, p\right.$ $<.001)$. Overall pleasantness ratings were not significantly affected by sucrose content $\left(F_{4,693}=\right.$ $1.82, p=.122)$. Importantly, the two phenotype groups did not differ in overall intensity perception $\left(F_{1,705}=0.09, p=.768\right)$ and the interaction between group and drink was not significant $\left(F_{4,705}=1.23, p=.299\right)$. In contrast, both the main effect of phenotype and the sucrose content* phenotype interaction were significant for pleasantness ratings $(F$ 's $>14.86, p$ 's $<.001)$. On average, sweet likers rated the solutions as significantly more pleasant than did the sweet dislikers (means: likers $=-0.03$, dislikers $=-1.07$, see Fig. 2 in the main text). Pairwise contrasts showed that the phenotype groups differed significantly in their pleasantness ratings of all sucrose solutions (all $t$ 's $>2.4$, all $p$ 's $<.04)$ except for the medium $(0.2 \mathrm{M}) \operatorname{drink}\left(t_{691}=1.20\right.$, $p=.230)$. Drink order ( $F$ 's $>3.8, p$ 's $<.001)$ significantly affected both types of ratings, but session order did not $(F ' s<2.54, p$ 's $>.08)$. ). Hunger, Nausea, BMI and age did not contribute to the fit of the model and did not significantly affect ratings $\left(F^{\prime} s<2.6, p\right.$ 's $\left.>.10\right)$. 


\section{No effects of MOR gene polymorphism on drug modulation of pleasantness and intensity}

The final LMMs for intensity and pleasantness ratings that assessed effects of genotype included the fixed effects: drug, sucrose content, genotype, genotype*drug, sucrose content*drug, drug*genotype* sucrose content, drink order, session and age. Genotype did not significantly affect sweetness perception (main effect $F_{1,2125}=0.36, p=.551$, genotype interaction effects, all $F^{\prime} s<1.5$, all $p$ 's $>.13$ ) or pleasantness ratings (main effect $F_{1,2060}=0.01, p=.915$, all $F$ 's $<$ 0.65 , all $p ’ s>.45)$. See Supplementary Figure 1.
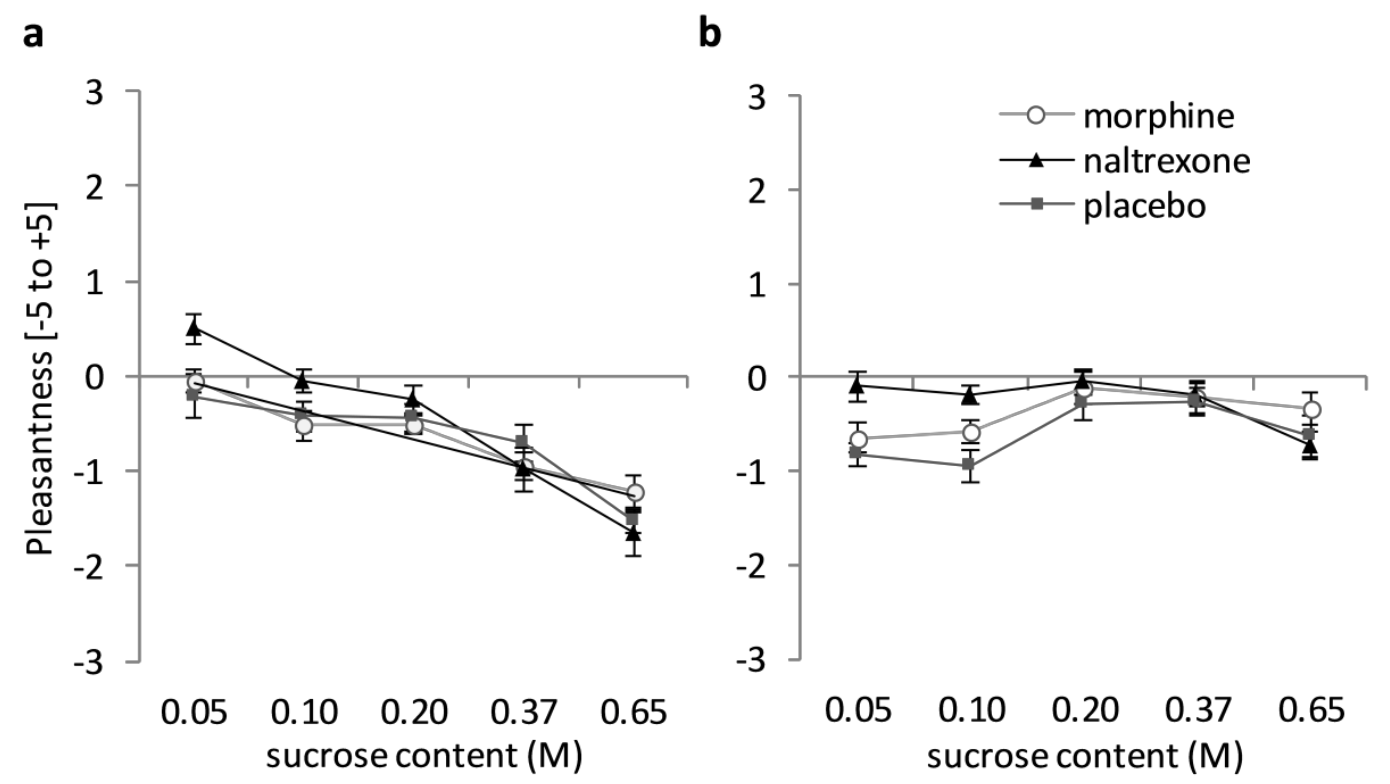

Supplementary Fig. 1 Estimated marginal means for pleasantness ratings in a) AA homozygous participants ( $n=27$ ) and b) G-carriers $(n=22)$ for each drug and sucrose solution. In our sample, there was no evidence that G-carriers differ from AA homozygous in sweet liking. Error bars are within-subject SEMs. 


\section{Effects of MOR manipulations on predicted pleasure of food and drink}

Supplementary table 1 contains overview of the final models for the three predicted pleasure analyses together with test statistics. For means and standard deviations from raw data see table 3 in the main text.

Supplementary Table 1: Predicted pleasure (SHAPS) mixed model analysis and results

\begin{tabular}{llll}
\hline & \multicolumn{3}{c}{ Outcome variable } \\
\cline { 2 - 4 } Fixed effects & $\begin{array}{l}\text { Overall } \\
\text { SHAPS score } \\
\text { analysis }\end{array}$ & $\begin{array}{l}\text { Favorite } \\
\text { beverage Item } \\
\text { analysis }\end{array}$ & $\begin{array}{l}\text { Favorite } \\
\text { food Item } \\
\text { analysis }\end{array}$ \\
\hline $\begin{array}{l}\text { Drug } \\
\text { Session }\end{array}$ & $F=1.63, p=.196$ & $F=6.52, p=.002$ & $F=4.50, p=.012$ \\
Time & $F=3.49, p=.031$ & $F=2.50, p=.083$ & $F=3.38, p=.039$ \\
nausea & $F=1.11, p=.331$ & $F=1.33, p=.264$ & $F=10.26, p<.001$ \\
hunger & - & $F=0.10, p=.755$ & $F=8.93, p=.003$ \\
drug*session & - & - & $F=7.21, p=.008$ \\
drug*time & $F=0.92, p=.451$ & $F=1.23, p=.296$ & - \\
session*time & - & - & $F=0.64, p=.634$ \\
drug*nausea & - & - & $F=0.67, p=.615$ \\
drug*session*time & - & $F=3.08, p=.047$ & - \\
$d f 2$ & 421 & - & $F=1.76, p=.052$ \\
\hline
\end{tabular}

Note: Test statistics and $p$-values are reported for all variables that contributed to the model fit of the predicted pleasure analyses (Overall SHAPS score and the two food related items). Variables that were not entered in the final models are marked by a hyphen. All models included a random intercept for the subject variable 